\title{
Sex Differences in Cannabis Use and Effects: A Cross-Sectional Survey of Cannabis Users
}

\author{
Carrie Cuttler, ${ }^{1, *}$ Laurie K. Mischley, ${ }^{2}$ and Michelle Sexton ${ }^{3}$
}

\begin{abstract}
Introduction: Despite known sex differences in the endocannabinoid system of animals, little attention has been paid to sex differences in human's cannabis use patterns and effects. The purpose of the present study was to examine sex differences in cannabis use patterns and effects in a large sample of recreational and medical cannabis users.

Methods: A large sample $(n=2374)$ of cannabis users completed an anonymous, online survey that assessed their cannabis use practices and experiences, including the short-term acute effects of cannabis and withdrawal effects. A subsample of 1418 medical cannabis users further indicated the medical conditions for which they use cannabis and its perceived efficacy.

Results: The results indicated that men reported using cannabis more frequently and in higher quantities than did women. Men were more likely to report using joints/blunts, vaporizers, and concentrates, while women were more likely to report using pipes and oral administration. Men were more likely than women to report increased appetite, improved memory, enthusiasm, altered time perception, and increased musicality when high, while women were more likely than men to report loss of appetite and desire to clean when high. Men were more likely than women to report insomnia and vivid dreams during periods of withdrawal, while women were more likely than men to report nausea and anxiety as withdrawal symptoms. Sex differences in the conditions for which medical cannabis is used, and its efficacy, were trivial.

Conclusions: These results may be used to focus research on biological and psychosocial mechanisms underlying cannabis-related sex differences, to inform clinicians treating individuals with cannabis use disorders, and to inform cannabis consumers, clinicians, and policymakers about the risks and benefits of cannabis for both sexes.
\end{abstract}

Key words: cannabis; cannabis acute effects; cannabis withdrawal; medical cannabis; sex differences

\section{Introduction}

The rapid growth of the cannabis industry, changes in public perceptions about the risks of cannabis, ${ }^{1}$ and increasing rates of cannabis use ${ }^{2}$ make it imperative that research is conducted to better understand the effects of cannabis in humans. This information will enable the expanding population of cannabis consumers, as well as healthcare professionals and policymakers, to make informed decisions about the risks and benefits of cannabis use. To fully understand the effects of can- nabis, potential sex differences must be considered. Animal research on the endocannabinoid system has revealed a sexually dimorphic system that interacts with gonadal hormones. ${ }^{3-5}$ Correspondingly, the small literature on sex differences in humans hints at intriguing differences in men's and women's experiences with cannabis.

\section{Cannabis use, dependence, and treatment}

The most well documented sex difference in human cannabis users is that men are more likely to use

\footnotetext{
${ }^{1}$ Department of Psychology, Washington State University, Pullman, Washington.

${ }^{2}$ Bastyr University Research Institute, Seattle, Washington.

${ }^{3}$ Center for the Study of Cannabis and Social Policy, Seattle, Washington.

*Address correspondence to: Carrie Cuttler, PhD, Department of Psychology, Washington State University, P.O. Box 644820, Johnson Tower, Pullman, WA 99164-4820, E-mail: carrie.cuttler@wsu.edu
}

(c) Carrie Cuttler et al. 2016; Published by Mary Ann Liebert, Inc. This Open Access article is distributed under the terms of the Creative Commons License (http://creativecommons.org/licenses/by/4.0), which permits unrestricted use, distribution, and reproduction in any medium, provided the original work is properly credited. 
and become dependent on cannabis. ${ }^{6-16}$ Men are also more likely to use cannabis for medicinal purposes ${ }^{17}$ and initiate use at a younger age. ${ }^{18-20}$ While there is some evidence that the "gender gap" in cannabis use is decreasing ${ }^{17,21,22}$ existing sex differences in cannabis use may reflect women's increased perceptions of risks associated with regular use. ${ }^{1,23,24}$ Further, while men are more likely to become dependent on cannabis, women demonstrate a more rapid progression from first use to cannabis use disorder. ${ }^{25-30}$ Consistent with these results, young males are more likely to enter treatment for cannabis abuse ${ }^{31}$ but women tend to enter treatment for cannabis abuse after fewer years of use and less cumulative use than men. ${ }^{26}$

\section{Withdrawal}

Research findings on sex differences in self-reported symptoms of cannabis withdrawal are equivocal: some studies suggest that women report experiencing more withdrawal symptoms than men, ${ }^{32,33}$ and others fail to find sex differences in withdrawal symptoms..$^{10,25,34,35}$ Some of the studies that failed to detect significant sex differences in withdrawal symptoms reported that the men in their samples reported greater use and dependence on cannabis. ${ }^{10,25}$ Therefore, it may be that women's decreased cannabis use and dependence helps to explain the lack of significant sex differences in withdrawal symptoms in those studies.

Agrawal et al. also failed to find sex differences in the overall prevalence of withdrawal symptoms; however, they did find that women were more likely to report nausea, and men were more likely to report goose bumps and pupil dilation, as withdrawal symptoms. ${ }^{35}$ Herrmann et al. also found that women reported more nausea, as well as stomach pain, irritability, restlessness, anger, and outbursts during their last quit attempt than did men. ${ }^{32}$ Finally, Copersino and colleagues found that women were more likely to report upset stomach whereas men were more likely to report cannabis cravings and increased sex drive during cannabis withdrawal. ${ }^{36}$ Therefore, while it is unclear whether women experience worse withdrawal than men, evidence indicates that women are prone to experience different withdrawal symptoms, particularly nausea and upset stomach.

\section{Acute effects}

Research involving the administration of cannabis or delta9-tetrahydrocannabinol (THC) suggests that women report significantly more dizziness than men. ${ }^{37}$ Findings on the subjective effects of cannabis or THC intoxication are equivocal: one study found that women give higher ratings than men for the subjective effects of smoked cannabis, ${ }^{38}$ one found that men report greater subjective effects of oral THC $(2.5,5,10 \mathrm{mg})$ than women $\mathrm{do}^{39}{ }^{39}$ and one indicated that sex differences in subjective effects of oral THC vary as a function of dose, with women reporting greater subjective effects than men at low doses ( $5 \mathrm{mg}$ ) and men reporting greater subjective effects than women at high doses $(15 \mathrm{mg}) .{ }^{40}$ Finally, Penetar et al. found shorter latencies to detect the effects of smoked cannabis and longer duration of the effects of smoked cannabis in men compared to women. ${ }^{41}$ These inconsistent results may reflect differences in in the populations tested (regular cannabis users $^{37,38,40,41}$ vs. non-users ${ }^{39}$ ), the route of administration used (smoked cannabis ${ }^{37,38,41}$ vs. orally administered $\mathrm{THC}^{37,39,40}$ ), and sex differences in frequency and quantity of cannabis used (only one study matched men and women on frequency and quantity of use $\mathrm{e}^{38}$ ). Clearly additional research is needed before strong conclusions regarding sex differences in the subjective effects of cannabis can be reached.

\section{Cognition}

To our knowledge only one sex difference in the acute effects of cannabis on cognition has been reported. Surprisingly, this study reported that a low dose of sublingually administered THC improved the spatial working memory performance of female but not male cannabis users. ${ }^{42}$ The remaining literature on sex differences in the influence of cannabis on cognition has focused on the chronic or residual effects and has once again produced somewhat equivocal results. For instance, Pope et al. are often cited for finding that female heavy cannabis users demonstrate worse visuospatial memory test performance relative to female light cannabis users (no differences were found in men ${ }^{43}$; however, the same researchers previously reported the opposite result using a different test of visuospatial memory. ${ }^{44}$ Crane et al. reported that cannabis use was associated with poorer decision-making in men but not women. ${ }^{45}$ Subsequently, Crane et al. reported that cannabis use was associated with better decision-making in women but not men. ${ }^{46}$ These researchers also found that cannabis use was associated with poorer episodic memory in women but not men. ${ }^{45,46}$ More consistently, male, but not female, cannabis users have demonstrated decreased speed than nonusers on timed cognitive tests. ${ }^{43,44,47,48}$ Therefore, while converging evidence suggests that chronic cannabis use may diminish speed of performance in men but not women, evidence from other domains of cognition is 
equivocal and future research is needed to better understand potential sex differences in the influence of cannabis on different cognitive domains.

\section{Study purpose}

While previous research suggests that men and women may use cannabis differently and experience different effects, many of the results pertaining to sex differences are equivocal. The primary purpose of the present survey study was to further document and describe sex differences in self-reported cannabis use and effects using a large sample of recreational and medical cannabis users. Moreover, we sought to explore potential sex differences in the medical conditions that medical cannabis patients report using cannabis to treat as well as in the perceived efficacy of cannabis in the treatment of those conditions. To our knowledge this is the first study to examine sex differences in medical cannabis use and effects.

\section{Methods}

Participants

A self-selected convenience sample of 2459 participants was recruited via word-of-mouth and links on advertisements posted on various websites and in Washington State cannabis dispensaries. The only inclusion criterion was use of cannabis in the past 90 days. Twenty-five respondents did not meet that criterion and were excluded. Thirty respondents were identified as providing more than one set of responses (based on redundant unique self-generated identification codes, age, and gender data) and the data from their second set of responses were excluded. An additional 30 respondents did not indicate their gender and were therefore excluded. The final sample included 2374 (1370 male, 1004 female) cannabis users. A total of $70.1 \%$ identified as recreational users, $59.7 \%$ as medical users, $2.4 \%$ as religious users (i.e., use of cannabis for primarily religious ceremonies and/or spiritual purposes), and $32.2 \%$ as both recreational and medical users. The sample was well balanced with respect to sex but was predominantly Caucasian. Table 1 shows the complete demographic characteristics of the sample broken down by sex.

\section{Procedure}

A brief, anonymous, online survey was used to assess cannabis use patterns and effects. No compensation was provided to participants. The survey was developed by examining strengths and weaknesses of existing surveys, previous literature, DSM criteria for cannabis withdrawal, medical indications for cannabis use, and clinical experience. Drafts were circulated to physicians, researchers,
Table 1. Demographic Characteristics of Male and Female Cannabis Users

\begin{tabular}{|c|c|c|c|}
\hline & Male & Female & $p$ \\
\hline Gender $(n)$ & $\begin{array}{c}1370 \\
57.7 \%\end{array}$ & $\begin{array}{c}1004 \\
43.3 \%\end{array}$ & \\
\hline Age $(n)$ & $\begin{array}{c}1354 \\
M=32.73 \\
(S D=13.20)\end{array}$ & $\begin{array}{c}990 \\
M=34.71 \\
(S D=13.12)\end{array}$ & $<0.001$ \\
\hline Ethnicity $(n)$ & 1350 & 997 & \\
\hline Caucasian & $87.5 \%$ & $85.9 \%$ & 0.25 \\
\hline African American & $1.2 \%$ & $1.2 \%$ & 0.97 \\
\hline Hispanic & $2.9 \%$ & $3.8 \%$ & 0.22 \\
\hline Native American & $0.7 \%$ & $1.8 \%$ & 0.011 \\
\hline Asian/Pacific Islander & $1.6 \%$ & $1.5 \%$ & 0.92 \\
\hline Other & $6.2 \%$ & $5.8 \%$ & 0.68 \\
\hline Highest level of education $(n)$ & 1356 & 999 & \\
\hline$<$ High school & $4.1 \%$ & $2.1 \%$ & 0.008 \\
\hline High school/GED & $33 \%$ & $24.3 \%$ & $<0.001$ \\
\hline Technical school & $12.3 \%$ & $10.1 \%$ & 0.10 \\
\hline Associate & $13.3 \%$ & $16.6 \%$ & 0.02 \\
\hline Bachelors & $26.9 \%$ & $31.8 \%$ & 0.009 \\
\hline Masters & $6.6 \%$ & $9.9 \%$ & 0.004 \\
\hline Doctorate & $3.8 \%$ & $5.1 \%$ & 0.14 \\
\hline Current employment ( $n$ ) & 1361 & 994 & \\
\hline Full time & $54.7 \%$ & $48.4 \%$ & 0.003 \\
\hline Part time & $20.4 \%$ & $23.6 \%$ & 0.06 \\
\hline Unemployed & $13.7 \%$ & $13.5 \%$ & 0.90 \\
\hline Retired & $4 \%$ & $3.5 \%$ & 0.52 \\
\hline Disabled & $7.3 \%$ & $11 \%$ & 0.002 \\
\hline Income: last 12 months $(n)$ & 1328 & 974 & \\
\hline$<\$ 20,000$ & $19.7 \%$ & $24.2 \%$ & 0.009 \\
\hline$\$ 20,000-40,000$ & $22.5 \%$ & $26.2 \%$ & 0.04 \\
\hline$\$ 40,000-60,000$ & $16.3 \%$ & $18.6 \%$ & 0.15 \\
\hline$\$ 60,000-80,000$ & $11.2 \%$ & $9.8 \%$ & 0.26 \\
\hline$\$ 80,000-100,000$ & $10.5 \%$ & $8.1 \%$ & 0.06 \\
\hline$\$ 100,000-150,000$ & $11.1 \%$ & $7 \%$ & $<0.001$ \\
\hline$>\$ 150,000$ & $8.7 \%$ & $6.2 \%$ & 0.03 \\
\hline Relationship status ( $n$ ) & 1367 & 998 & \\
\hline Married & $29.3 \%$ & $32.6 \%$ & 0.09 \\
\hline Domestic partnership & $12.4 \%$ & $16.9 \%$ & 0.002 \\
\hline Divorced & $3.8 \%$ & $6.6 \%$ & 0.002 \\
\hline Single & $47.1 \%$ & $36.6 \%$ & $<0.001$ \\
\hline Other & $7.3 \%$ & $7.3 \%$ & 1.0 \\
\hline
\end{tabular}

Bold values indicate statistical significance. $\mathrm{SD}$, standard deviation.

and cannabis users for feedback in an iterative process. Bastyr University's Internal Review Board approved the protocol.

Some aspects of the collected data are not reported here because they are being published separately. Specifically, data on the medical conditions and perceived efficacy of cannabis in treating medical conditions (disregarding sex) and data on driving beliefs and habits are presented in two separate manuscripts that are currently under review. Data on the use of cannabis as a substitute for alcohol and other drugs are currently in preparation for a separate manuscript. Only questions relevant to the present study are described in the Materials section that follows. 


\section{Materials}

Demographic questions. Participants were asked to input their age and country of residence. Participants were asked to use nominal scales to indicate their gender, ethnicity, employment status, and relationship status. Finally, they used ordinal scales to indicate their highest level of education and total family income. The response options for these questions are shown in Table 1.

Cannabis use patterns. Participants were asked to use a nominal scale to indicate whether or not (yes/no) they used cannabis for recreation purposes, medicinal purposes, and religious purposes. They were asked to use a nominal scale to indicate the method of administration they most commonly use. They were also asked to use ordinal scales to indicate frequency of cannabis use, quantity of cannabis used per week, and age of first use. Complete response options for each of these items are shown in Table 2. Finally, participants indi-

Table 2. Cannabis Use Patterns of Male and Female Cannabis Users

\begin{tabular}{|c|c|c|c|}
\hline & Male & Female & $p$ \\
\hline Frequency of use $(n)$ & 1364 & 1004 & \\
\hline All day, everyday & $10.4 \%$ & $7.2 \%$ & 0.007 \\
\hline 5-10 times per day & $14.1 \%$ & $10.3 \%$ & 0.005 \\
\hline 1-4 times per day & $42.7 \%$ & $43.3 \%$ & 0.78 \\
\hline 3-6 times per week & $14.6 \%$ & $14.5 \%$ & 0.97 \\
\hline 1-3 times per week & $10.3 \%$ & $10.7 \%$ & 0.80 \\
\hline 2-3 times per month & $4.0 \%$ & $6.0 \%$ & 0.02 \\
\hline Once a month & $1.2 \%$ & $2.7 \%$ & 0.006 \\
\hline Less than once a month & $2.6 \%$ & $5.4 \%$ & $<0.001$ \\
\hline Quantity (per week) (n) & 1359 & 992 & \\
\hline More than 1 ounce $(28 \mathrm{~g})$ & $1.9 \%$ & $2.4 \%$ & 0.40 \\
\hline 1 ounce $(28 \mathrm{~g})$ & $5.4 \%$ & $3.3 \%$ & 0.015 \\
\hline $1 / 4$ ounce $(7 \mathrm{~g})$ & $25.5 \%$ & $16.7 \%$ & $<0.001$ \\
\hline $3-5 \mathrm{~g}$ & $29.7 \%$ & $30.9 \%$ & 0.50 \\
\hline $1-2 \mathrm{~g}$ & $21.7 \%$ & $21.8 \%$ & 0.97 \\
\hline Less than $1 \mathrm{~g}$ & $15.7 \%$ & $24.8 \%$ & $<0.001$ \\
\hline Hits per session $(n)$ & $\begin{array}{c}1364 \\
M=6.08 \\
(S D=3.39)\end{array}$ & $\begin{array}{c}975 \\
M=5.00 \\
(S D=2.89)\end{array}$ & $<0.001$ \\
\hline Age of first use, years $(n)$ & 1369 & 1000 & \\
\hline$<14$ & $14.2 \%$ & $15.4 \%$ & 0.40 \\
\hline $14-16$ & $38.3 \%$ & $38 \%$ & 0.89 \\
\hline $17-18$ & $25.1 \%$ & $20.8 \%$ & 0.02 \\
\hline $19-20$ & $9.8 \%$ & $10.3 \%$ & 0.68 \\
\hline $21-25$ & $7.7 \%$ & $9.1 \%$ & 0.21 \\
\hline $26-30$ & $3.0 \%$ & $2.4 \%$ & 0.38 \\
\hline$>30$ & $2.1 \%$ & $4 \%$ & 0.005 \\
\hline Method of use $(n)$ & 1366 & 1003 & \\
\hline Joints/blunts & $23 \%$ & $16.5 \%$ & $<0.001$ \\
\hline Pipe & $28.4 \%$ & $42.3 \%$ & $<0.001$ \\
\hline Bong & $21.1 \%$ & $17.8 \%$ & 0.05 \\
\hline Vaporizer & $17.3 \%$ & $11.4 \%$ & $<0.001$ \\
\hline Oral (edibles, tinctures, capsules) & $3.9 \%$ & $7.9 \%$ & $<0.001$ \\
\hline Concentrates & $5.4 \%$ & $3.1 \%$ & 0.007 \\
\hline Topical & $0.4 \%$ & $0.4 \%$ & 1.0 \\
\hline Other & $0.6 \%$ & $0.7 \%$ & 0.73 \\
\hline
\end{tabular}

Bold values indicate statistical significance. cated the number of hits they take per smoking session, using a ratio scale ranging from 1 (1 hit) to 11 (more than 10 hits).

Addiction and withdrawal. Participants used a nominal (yes/no) scale to indicate whether they had ever had trouble reducing or stopping their use of cannabis, and they used a nominal (yes/no/I don't know) scale to indicate whether they believed that cannabis is addictive.

Participants were asked to report the withdrawal symptoms experienced with discontinuation of cannabis for $72 \mathrm{~h}$ or more. They were shown a list of 13 withdrawal symptoms and were asked to use a nominal (yes/no) scale to indicate which they have experienced. The list of withdrawal symptoms is shown in Table 3. A not applicable $(\mathrm{n} / \mathrm{a})$ response option was also included for those who had not experienced withdrawal or who had never discontinued cannabis for $72 \mathrm{~h}$ or more. Finally, a composite withdrawal score was computed by summing the number of withdrawal symptoms each participant endorsed.

Acute effects. Participants were shown a list of 41 possible effects of cannabis and were asked to use a nominal (yes/no) scale to indicate which they experience when they are stoned. The list of acute effects is shown in Table 4.

Medical use and perceived efficacy. Participants were shown a list of 19 medical conditions and were asked to

Table 3. Sex Differences in Addiction and Withdrawal Symptoms

\begin{tabular}{lrrr}
\hline & Male, & Female, & \\
& $\boldsymbol{n}=\mathbf{1 3 7 0}$ & $\boldsymbol{n}=\mathbf{1 0 0 4}$ & $\boldsymbol{p}$ \\
\hline Addictiveness & & \\
Difficulty in reducing or stopping & $17.7 \%$ & $15.2 \%$ & 0.11 \\
Believe cannabis is not addictive & $70.6 \%$ & $67.7 \%$ & 0.13 \\
Believe cannabis is addictive & $18.2 \%$ & $14.8 \%$ & 0.03 \\
Do not know if cannabis is addictive & $11.3 \%$ & $17.5 \%$ & $<\mathbf{0 . 0 0 1}$ \\
Withdrawal symptoms & & & \\
Irritability & $35.9 \%$ & $32.2 \%$ & 0.06 \\
Insomnia/interrupted sleep & $32 \%$ & $27 \%$ & $\mathbf{0 . 0 0 9}$ \\
Nausea & $5.3 \%$ & $8.4 \%$ & $\mathbf{0 . 0 0 3}$ \\
Loss of appetite & $20.8 \%$ & $18.3 \%$ & 0.14 \\
Sweating & $4.7 \%$ & $3.1 \%$ & 0.05 \\
Salivation & $0.7 \%$ & $0.5 \%$ & 0.48 \\
Tremor & $1.5 \%$ & $1 \%$ & 0.25 \\
Weight loss & $3.9 \%$ & $3.9 \%$ & 0.94 \\
Tiredness & $8.6 \%$ & $8.8 \%$ & 0.90 \\
Vivid dreams & $21.7 \%$ & $13.3 \%$ & $<\mathbf{0 . 0 0 1}$ \\
Anxiety & $20.5 \%$ & $25 \%$ & $\mathbf{0 . 0 0 9}$ \\
Loss of productivity & $13.1 \%$ & $11.4 \%$ & 0.19 \\
Improved productivity & $5.3 \%$ & $3.8 \%$ & 0.08 \\
\hline
\end{tabular}

Bold values indicate statistical significance. 
Table 4. Sex Differences in the Acute Effects of Cannabis

\begin{tabular}{|c|c|c|c|}
\hline & $\begin{array}{c}\text { Male, } \\
n=1370\end{array}$ & $\begin{array}{l}\text { Female, } \\
n=1004\end{array}$ & $p$ \\
\hline \multicolumn{4}{|l|}{ Cognitive } \\
\hline More forgetful & $37.8 \%$ & $36.5 \%$ & 0.50 \\
\hline Short-term memory problems & $42.9 \%$ & $41.7 \%$ & 0.56 \\
\hline Long-term memory problems & $4.2 \%$ & $4.7 \%$ & 0.54 \\
\hline Memory improvement & $15.5 \%$ & $11.8 \%$ & 0.009 \\
\hline Difficulty concentrating & $17 \%$ & $15.8 \%$ & 0.45 \\
\hline Improved concentration & $42.9 \%$ & $37.7 \%$ & 0.011 \\
\hline Difficulty making decisions & $9.7 \%$ & $12.5 \%$ & 0.03 \\
\hline Confusion & $5.1 \%$ & $5.1 \%$ & 0.97 \\
\hline Sense of clarity/perspective & $43.8 \%$ & $45.9 \%$ & 0.30 \\
\hline Difficulty finding words & $16.8 \%$ & $19.5 \%$ & 0.09 \\
\hline More articulate or communicative & $42.7 \%$ & $41 \%$ & 0.42 \\
\hline \multicolumn{4}{|l|}{ Social } \\
\hline Better social interactions & $49.7 \%$ & $45 \%$ & 0.03 \\
\hline Worse social interactions & $11.8 \%$ & $14.1 \%$ & 0.09 \\
\hline More extraverted, "outward" focus & $24.9 \%$ & $24.5 \%$ & 0.83 \\
\hline More "inward" focus & $50.7 \%$ & $49.1 \%$ & 0.43 \\
\hline \multicolumn{4}{|l|}{ Psychological } \\
\hline More calm or peaceful & $79.6 \%$ & $79.2 \%$ & 0.79 \\
\hline Less anxious or fearful & $55.3 \%$ & $57.2 \%$ & 0.37 \\
\hline Increased anxiety & $8.8 \%$ & $9.2 \%$ & 0.73 \\
\hline Paranoia & $14.5 \%$ & $15.2 \%$ & 0.59 \\
\hline Apathetic (lack of interest/concern) & $9.9 \%$ & $8.9 \%$ & 0.38 \\
\hline Loss of motivation & $23.6 \%$ & $24.8 \%$ & 0.48 \\
\hline Increased motivation & $47 \%$ & $47.6 \%$ & 0.77 \\
\hline Enthusiastic & $41.8 \%$ & $34.5 \%$ & $<0.001$ \\
\hline Altered sense of time & $41 \%$ & $34.2 \%$ & 0.001 \\
\hline Hallucinations & $4 \%$ & $3.4 \%$ & 0.38 \\
\hline \multicolumn{4}{|l|}{ Movement } \\
\hline Poor balance (feel unsteady) & $5.3 \%$ & $6.2 \%$ & 0.34 \\
\hline Lack of coordination & $5.3 \%$ & $5.8 \%$ & 0.64 \\
\hline Desire to stretch/exercise & $36.5 \%$ & $38.9 \%$ & 0.22 \\
\hline Desire to be still (couch-lock) & $32.6 \%$ & $29.1 \%$ & 0.07 \\
\hline Desire to clean & $36.4 \%$ & $47 \%$ & $<0.001$ \\
\hline \multicolumn{4}{|l|}{ Physiological } \\
\hline Tired or sleepy & $43.2 \%$ & $48.1 \%$ & 0.02 \\
\hline Stimulated or energized & $45.3 \%$ & $42 \%$ & 0.11 \\
\hline Dry mouth & $64.7 \%$ & $62.8 \%$ & 0.34 \\
\hline Dizziness & $4.7 \%$ & $4.4 \%$ & 0.68 \\
\hline Increased sex drive & $51.3 \%$ & $46.4 \%$ & 0.02 \\
\hline Diminished sex drive & $6.9 \%$ & $5.7 \%$ & 0.24 \\
\hline Desire to eat (munchies) & $75.2 \%$ & $70 \%$ & 0.005 \\
\hline Loss of appetite & $8.5 \%$ & $11.8 \%$ & 0.009 \\
\hline \multicolumn{4}{|l|}{ Artistic } \\
\hline More creative & $75.5 \%$ & $71.3 \%$ & 0.02 \\
\hline Less creative & $3.3 \%$ & $3 \%$ & 0.68 \\
\hline Musical & $49.3 \%$ & $37 \%$ & $<0.001$ \\
\hline
\end{tabular}

Bold values indicate statistical significance.

indicate which they use cannabis to treat. The list of medical conditions is shown in Table 5.

To assess perceived efficacy of cannabis, participants were also asked to indicate the effect that cannabis has on their medical conditions, using a scale ranging from -5 (worsening symptoms) to 0 (no change) to +5 (improvement of symptom). Each symptom was assessed separately and an additional composite score was created by computing the mean rating across all conditions.
Table 5. Sex Differences in Medical Conditions Cannabis Is Used to Treat

\begin{tabular}{lrrc}
\hline & Male, & Female, & \\
& $\boldsymbol{n}=\mathbf{7 7 4}$ & $\boldsymbol{n}=\mathbf{6 4 4}$ & $\boldsymbol{p}$ \\
\hline Multiple sclerosis & $0.7 \%$ & $1.7 \%$ & 0.06 \\
Cancer & $3.4 \%$ & $3.4 \%$ & 0.85 \\
Epilepsy & $0.9 \%$ & $1.7 \%$ & 0.18 \\
HIV & $1.2 \%$ & $0.2 \%$ & 0.02 \\
Glaucoma & $2.3 \%$ & $1.1 \%$ & 0.08 \\
IBS & $12 \%$ & $18.2 \%$ & $\mathbf{0 . 0 0 1}$ \\
Colitis/Crohn's disease & $3.1 \%$ & $3.3 \%$ & 0.86 \\
Tremor & $2.3 \%$ & $2.3 \%$ & 1.0 \\
Anxiety & $50.6 \%$ & $66.6 \%$ & $<\mathbf{0 . 0 0 1}$ \\
Depression & $48.7 \%$ & $52.3 \%$ & 0.17 \\
Spasticity & $16.5 \%$ & $21 \%$ & 0.03 \\
Nausea & $20.7 \%$ & $35.2 \%$ & $<\mathbf{0 . 0 0 1}$ \\
Pain & $59.3 \%$ & $63.8 \%$ & 0.08 \\
Intractable pain & $11 \%$ & $12.3 \%$ & 0.45 \\
Tics & $2.8 \%$ & $2.2 \%$ & 0.43 \\
Anorexia & $7.8 \%$ & $12.6 \%$ & $\mathbf{0 . 0 0 2}$ \\
Seizures/spasticity & $2.8 \%$ & $2.3 \%$ & 0.55 \\
Headaches/migraines & $27.4 \%$ & $45 \%$ & $<\mathbf{0 . 0 0 1}$ \\
Arthritis & $15.4 \%$ & $19.3 \%$ & 0.054 \\
\hline
\end{tabular}

Bold values indicate statistical significance.

IBS, Irritable Bowel Syndrome.

Data analysis

The data were analyzed using IBM SPSS 23 . Nominal scale data were analyzed by computing the percentages of men and women who endorsed each response, and sex differences in these percentages were determined using chi-square tests. Sex differences in ordinal data were determined using Mann-Whitney $U$ tests, and sex differences on interval and ratio scale data were determined using $t$-tests.

Due to the large number of comparisons and the large sample size, only results with a $p$-value below 0.01 were considered statistically significant. Ratio and interval scale data were screened for univariate outliers, defined as scores falling more than 3.29 standard deviations from the mean, and the small number of outlying values detected $(<0.5 \%$ of screened data) were replaced with the nearest non-outlying value. ${ }^{49}$

\section{Results}

\section{Cannabis use patterns}

There were significant differences in the percentages of men and women who indicated using cannabis for recreational purposes $(73.4 \%$ men; $65.5 \%$ women, $p<0.001)$ and who indicated using cannabis for medicinal purposes $(54.3 \%$ men; $64.1 \%$ women, $p<0.001$ ), but there was no sex difference in the percentages of men and women who reported using cannabis for religious reasons $(2.5 \%$ men; $2.3 \%$ women, $p=0.76)$. 
The results further indicated that men use cannabis more frequently $(p<0.001)$, and in higher quantities $(p<0.001$; Table 2). Men were also found to report taking significantly more hits per smoking session than women, $t(2316)=8.06, p<0.001$. Overall, there was no significant sex difference in the reported age of first use $(p=0.76)$; however, women were twice as likely as men to report first using cannabis after the age of 30. The results of analyses on method of administration further indicate that men were significantly more likely than women to report using joints/blunts, vaporizers, and concentrates, while women were significantly more likely than men to report using pipes and oral methods of administration (Table 2).

\section{Addiction and withdrawal}

As shown in Table 3, there were no significant sex differences in reported trouble reducing or stopping cannabis use, in beliefs that cannabis is addictive, or in beliefs that cannabis is not addictive. However, significantly more women than men reported not knowing if cannabis is addictive.

The results of analyses on the specific withdrawal symptoms revealed that men were significantly more likely than women to report experiencing insomnia and vivid dreams, while women were significantly more likely than men to report nausea and anxiety as withdrawal symptoms (Table 3). A total of $34.4 \%$ of the sample responded using the "n/a" option, indicating that they had not experienced withdrawal and/or had never discontinued cannabis for $72 \mathrm{~h}$ or more. Significantly more women (39.3\%) than men (31\%) responded with the "n/a" option $(p<0.001)$. An examination of the composite score that was computed revealed that $40.2 \%$ of the sample $(36.7 \%$ of men; $44.9 \%$ of women, $p<$ 0.001 ) indicated no withdrawal symptoms; while the remaining $59.7 \%$ of participants $(63.3 \%$ of men; $55.1 \%$ of women, $p<0.001)$ indicated that they experienced at least one withdrawal symptom. Overall, there was no significant difference in the mean number of withdrawal symptoms reported by men $(M=1.73)$ and women $(M=1.55), t(2372)=2.26, p=0.02$.

\section{Acute effects}

The results of analyses on the acute effects data indicate that men were significantly more likely than women to report experiencing memory improvement, a desire to eat, increased enthusiasm, altered sense of time, and increased musicality; in contrast women were significantly more likely than men to report experiencing a loss of appetite and desire to clean (Table 4).

\section{Medical use and perceived efficacy}

Only the 1418 participants who indicated that they use cannabis for medicinal purposes were included in the analyses of medical use and perceived efficacy. As shown in Table 5, women were significantly more likely than men to report using cannabis to treat anxiety, nausea, anorexia, irritable bowel syndrome (IBS), and headaches/migraines.

As shown in Table 6, men reported experiencing greater headache/migraine relief from medical cannabis than women. An analysis of the composite score representing the mean rating across all conditions confirmed

Table 6. Sex Differences in Perceived Efficacy of Cannabis to Treat Various Medical Conditions

\begin{tabular}{|c|c|c|c|}
\hline & Male, $n=774$ & Female, $n=644$ & $p$ \\
\hline Multiple sclerosis & $n=5 ; M=3.96(S D=0.96)$ & $n=11 ; M=3.28(S D=1.37)$ & 0.34 \\
\hline Cancer & $n=21 ; M=3.60(S D=1.47)$ & $n=18 ; M=3.72(S D=1.29)$ & 0.79 \\
\hline Epilepsy & $n=7 ; M=4.63(S D=0.73)$ & $n=11 ; M=4.30(S D=1.09)$ & 0.49 \\
\hline HIV & $n=9 ; M=2.80(S D=1.75)$ & $n=0$ & - \\
\hline Glaucoma & $n=2 ; M=1.50(S D=2.26)$ & $n=0$ & - \\
\hline IBS & $n=88 ; M=3.53(S D=1.31)$ & $n=115 ; M=3.45(S D=1.34)$ & 0.67 \\
\hline Colitis/Crohn's disease & $n=23 ; M=4.28(S D=0.91)$ & $n=20 ; M=4.09(S D=1.09)$ & 0.52 \\
\hline Tremor & $n=16 ; M=3.45(S D=1.87)$ & $n=15 ; M=3.72(S D=1.25)$ & 0.64 \\
\hline Anxiety & $n=385 ; M=3.48(S D=1.37)$ & $n=423 ; M=3.57(S D=1.32)$ & 0.37 \\
\hline Depression & $n=369 ; M=3.84(S D=1.27)$ & $n=330 ; M=3.67(S D=1.28)$ & 0.08 \\
\hline Spasticity & $n=125 ; M=3.57(S D=1.24)$ & $n=132 ; M=3.58(S D=1.19)$ & 0.95 \\
\hline Nausea & $n=157 ; M=4.24(S D=1.03)$ & $n=223 ; M=4.20(S D=0.98)$ & 0.68 \\
\hline Pain & $n=450 ; M=3.46(S D=1.18)$ & $n=406 ; M=3.54(S D=1.11)$ & 0.28 \\
\hline Tics & $n=22 ; M=3.75(S D=1.46)$ & $n=14 ; M=3.51(S D=1.39)$ & 0.64 \\
\hline Appetite & $n=60 ; M=4.40(S D=0.86)$ & $n=80 ; M=4.18(S D=1.05)$ & 0.20 \\
\hline Seizures/spasticity & $n=21 ; M=4.41(S D=0.87)$ & $n=14 ; M=3.66(S D=1.00)$ & 0.02 \\
\hline Headaches/migraines & $n=206 ; M=3.79(S D=1.24)$ & $n=289 ; M=3.47(S D=1.23)$ & 0.004 \\
\hline
\end{tabular}


no significant differences in men's $(M=3.61)$ and women's $(M=3.58)$ ratings of the perceived efficacy of medical cannabis, $t(1319)=0.58, p=0.56$.

\section{Discussion}

The purpose of the present study was to examine sex differences in cannabis use and effects using a large sample of recreational and medical cannabis users. Overall, the results indicated that there are small but significant sex differences in cannabis use patterns, acute effects, and withdrawal effects. In contrast, only trivial sex differences in medical cannabis use, and in perceived efficacy of medical cannabis, were detected.

Consistent with previous research our findings indicate that men use cannabis more frequently and in higher quantities than do women. We did not replicate previous findings that men are more likely to initiate use at a younger age. ${ }^{18-20}$ This may be indicative of recent changes in the socio-cultural perception of cannabis use among female adolescents. However, our results do provide evidence that women are twice as likely as men to initiate use after the age of 30 . This may reflect new trends in diminishing stigma toward cannabis use and decreases in older women's perceptions of risks associated with cannabis use. Alternatively, it may reflect our finding of a higher percentage of women than men reporting using cannabis for medical purposes and a lower percentage of women than men reporting using cannabis for recreational purposes.

The present study provides new insights into sex differences in the methods used to administer cannabis. Specifically, men were more likely than women to report primarily smoking joints/blunts and using concentrates and vaporizers, whereas women are more likely than men to report primarily using pipes and oral methods of administration (edibles, tinctures, capsules). Joints/blunts and some concentrates require more skill to prepare, while pipes, and oral ingestion are easier and more discrete methods. As such, sex differences in methods of administration may reflect women's tendency to be less experienced and/or more discrete about their cannabis use.

Findings from the present study also revealed a number of sex differences in the acute effects of cannabis intoxication. Somewhat surprisingly, men were more likely than women to report memory improvement when high. This result is contradictory to previous controlled laboratory research that indicates that an acute dose of sublingually administered THC improves the spatial working memory performance of female, but not male, cannabis users. ${ }^{42}$ Therefore, it is possible that our effect is biased by the self-report nature of our survey. In other words, men may simply be more likely to perceive and report these experiences than women. Similarly, previous research suggests that cannabis users may be more susceptible to false memories/memory distortions, ${ }^{50}$ leaving open the possibility that part of the experienced improvement involves the recall of false, rather than veridical, memories. To our knowledge no research has examined potential sex differences in false memories of cannabis users, but such research may prove to be enlightening. Further, our study did not distinguish between the many different types of memory (e.g., implicit, explicit, verbal, spatial) and as such future research should include more fine-grained analyses into the various types of memory impairments and improvements that men and women report experiencing when under the influence of cannabis.

Men in the present study were also significantly more likely to report experiencing altered time perception, increased musicality, and enthusiasm when high. These findings are also novel and somewhat surprising. While it is known that acute cannabis intoxication alters time perception, ${ }^{51}$ to our knowledge, sex differences in this effect have not been previously discovered. Future research employing time estimation tasks is needed to examine this effect objectively. Finally, our finding that women were more likely than men to report a desire to clean likely reflects the fact that women are more likely to be responsible for cleaning duties. It is also possible that some women interpreted this item to include personal cleaning and self-care, which in general women are also likely to perform more frequently.

It is widely known that acute cannabis intoxication results in increased appetite. Our results further reveal that a larger percentage of men than women reported increased appetite, while a larger percentage of women than men reported decreased appetite when high. These sex differences are consistent with the results of animal research showing that a cannabinoid agonist increased the consumption of sweetened condensed milk in male rats in the first, second, and third hour post-injection, while it only increased consumption in the female rats in the third hour post-injection. ${ }^{52}$ Similar sex differences in cannabinoid-induced hyperphagia have been reported in guinea pigs. ${ }^{53}$ Finally, these findings are consistent with research showing that an acute dose of the cannabinoid agonist dronabinol resulted in a higher fasting gastric volume (associated with reduced satiation) in men 
and slowed gastric emptying (associated with decreased appetite) in women. ${ }^{54}$ Future research may consider examining the types of cravings (e.g., sweets, carbohydrates) that cannabis users experience and whether they vary as a function of sex.

Sex differences in the specific withdrawal symptoms reported by men and women were also detected. For instance, men were more likely than women to report experiencing sleep disturbances and vivid dreams during withdrawal. This result is consistent with previous research showing that men abstaining from cannabis spend less time sleeping and less time in rapid eye movement (REM) sleep than women abstaining from cannabis. ${ }^{55}$ Dream intensity increases with REM deprivation $^{56}$; therefore, men's more frequently experience of vivid dreams may be a function of their decreased time in REM sleep during withdrawal.

Our findings indicate that women are more likely than men to report experiencing nausea and anxiety during withdrawal. Consistent with these effects female medical cannabis users were more likely than male medical cannabis users to report using cannabis to treat nausea and anxiety. However no sex differences in the perceived efficacy of cannabis in treating nausea or anxiety were detected. Likewise, female medical cannabis users were more likely than male medical cannabis users to report using cannabis to treat anorexia, IBS, and headaches/migraines. However, no sex differences in the perceived efficacy of cannabis in treating anorexia or IBS were detected, and men reported that cannabis is more effective in treating headaches/migraines. These patterns of results likely reflect women's higher base rates and increased susceptibility to experience and report nausea, ${ }^{57-59}$ anxiety, ${ }^{60}$ anorexia, ${ }^{60}$ IBS $^{61}$ and headaches/migraines ${ }^{62-64}$ rather than cannabis-specific effects.

As with most survey studies, the present study is limited by potential bias in self-reports, including but not limited to, exaggeration of beneficial effects, diminishment of negative effects, recall bias, and in the case of the medical data potential placebo effects. An additional limitation concerns our findings of sex differences in frequency, quantity, and method of use and the impact that these differences may have on our findings of acute and withdrawal effects. It is possible that men's increased frequency and quantity of use and their preference for different routes of administration may be impacting or driving some of the sex differences in the acute and withdrawal effects. For instance, it is possible that we did not replicate previous findings of increased withdrawal symptoms in women ${ }^{32,33}$ because of their lower frequency and quantity of use. Future more controlled research will need to examine these possibilities and further validate our results.

While our findings provide intriguing insights into sex differences in the use and effects of cannabis, caution should be taken when generalizing results from this self-selected convenience sample to the general population. Our exclusion of individuals who had not used cannabis in the past 90 days was practical and ensured that the survey questions would be relevant to participants; however, it limits the generalization of our findings to recent cannabis users. The sample was also predominantly Caucasian and lacked ethnic diversity. It is possible that individuals from minority groups, who are more likely to be arrested for cannabisrelated offenses, ${ }^{65,66}$ were more hesitant to participate. While individuals from a variety of different countries and regions completed the survey, the origin of the survey was Washington State, and the majority of participants were from this state. Regional differences in the availability of different forms of cannabis and in medical cannabis laws may have therefore affected some of the outcomes. Despite our use of a convenience sample of predominantly Caucasian, recent cannabis users residing in Washington State, our sample was very large and well balanced with respect to sex, which increases our confidence in the generalizability of the present findings to this specific population of cannabis users.

These results can be used to guide future research on biological and psychosocial mechanisms underlying cannabis-related sex differences and to inform clinicians treating individuals with cannabis use disorders. Our findings indicate that men attempting to quit cannabis may benefit from sleep aids, while women may benefit from anti-emetics and training in anxiety coping strategies. Finally, the results should be used to inform the growing population of cannabis consumers, policymakers, and medical cannabis service providers, about some of the risks and benefits of cannabis for both sexes so they can make more informed decisions about the use and regulation of cannabis.

\section{Acknowledgments}

The authors would like to thank and acknowledge Dr. Rebecca Craft, Dr. Ryan McLaughlin, and Alexander Spradlin for their thoughtful comments and edits of a previous draft of this manuscript.

\section{Author Disclosure Statement}

No competing financial interests exist. 


\section{References}

1. Okaneku J, Vearrier D, McKeever RG, et al. Change in perceived risk associated with marijuana use in the United States from 2002 to 2012. Clin Toxicol. 2015;53:151-155.

2. Substance Abuse and Mental Health Services Administration (SAMHSA) Behavioral health trends in the United States: results from the 2014 national survey on drug use and health. 2015. Available at www.samhsa .gov/data/sites/default/files/NSDUH-FRR1-2014/NSDUH-FRR1-2014.pdf (last accessed February 2016).

3. Craft RM, Marusich JA, Wiley JL. Sex differences in cannabinoid pharmacology: a reflection of differences in the endocannabinod system? Life Sci. 2013;92:476-481.

4. Fattore L, Fratta W. How important are sex differences in cannabinoid action? Br J Pharmacol. 2010;160:544-548.

5. Gorzalka BB, Dang SS. Endocannabinoids and gonadal hormones: bidirectional interactions in physiology and behavior. Endocrinology. 2012; 153:1016-1024.

6. Agrawal A, Lynskey MT. Does gender contribute to heterogeneity in criteria for cannabis abuse and dependence? Results from the National Epidemiological Survey on Alcohol and Related Conditions. Drug Alcohol Depend. 2007;88:300-307.

7. Anthony JC, Helzer JE. Syndromes of drug abuse and dependence. In Robins LN, Regier DA (Eds.), Psychiatric disorders in America: the epidemiological catchment area study. Free Press: New York, 1991.

8. Coffey C, Carlin JB, Lynskey M, et al. Adolescent precursors of cannabis dependence: findings from the Victorian Adolescent Health Cohort Study. Br J Psychiatry. 2003;182:330-336.

9. Compton WM, Grant BF, Colliver JD, et al. Prevalence of marijuana use disorders in the United States: 1991-1992 and 2001-2002. JAMA. 2004;291:2114-2121.

10. Crowley TJ, Macdonald MJ, Whitmore EA, et al. Cannabis dependence, withdrawal, and reinforcing effects among adolescents with conduct symptoms and substance use disorders. Drug Alcohol Depend. 1998;50:27-37.

11. Fergusson DM, Horwood LJ. Cannabis use and dependence in a New Zealand birth cohort. N Z Med J. 2000;113:156-158.

12. Grant JD, Scherrer JF, Neuman RJ, et al. A comparison of the latent class structure of cannabis problems among adult men and women who have used cannabis repeatedly. Addiction. 2006;101:1133-1142.

13. Kandel $D$, Chen $K$, Warner LA, et al. Prevalence and demographic correlates of symptoms of last year dependence on alcohol, nicotine, marijuana and cocaine in the U.S. population. Drug Alcohol Depend. 1997;44:11-29.

14. McCrady BS, Epstein EE. Addictions: a comprehensive guidebook. Oxford University Press: New York, 1999.

15. Wagner FA, Anthony JC. Male-female differences in the risk of progression from first use to dependence upon cannabis, cocaine, and alcohol. Drug Alcohol Depend. 2007;86:191-198.

16. Warner LA, Kessler RC, Hughes M, et al. Prevalence and correlates of drug use and dependence in the United States. Results from the National Comorbidity Survey. Arch Gen Psychiatry. 1995;52:219-229.

17. Fairman BJ. Trends in registered medical marijuana participation across 13 US states and District of Columbia. Drug Alcohol Depend. 2016;159:72-79.

18. Gfroerer JC, Epstein JF. Marijuana initiates and their impact on future drug abuse treatment need. Drug Alcohol Depend. 1999;54:229-237.

19. Gfroerer JC, Wu LT, Penne MA. Initiation of marijuana use: trends, patterns, and implications (Analytic Series: A-17, DHHS Publication No. SMA 02-3711). Substance Abuse and Mental Health Services Administration, Office of Applied Studies: Rockville, MD, 2002.

20. Pope HG, Gruber AJ, Hudson Jl, et al. Early-onset cannabis use and cognitive deficits: what is the nature of the association? Drug Alcohol Depend. 2003;69:303-310.

21. Greenfield SF, O'Leary G. Sex differences in marijuana use in the United States. Harv Rev Psychiatry. 1999;6:297-303.

22. Johnson RM, Fairman B, Gilreath T, et al. Past 15-year trends in adolescent marijuana use: differences by race/ethnicity and sex. Drug Alcohol Depend. 2015;155:8-15.

23. Galván GD, Guerrero $M$, Pinedo $\sqcup$, et al. Cannabis: alternative realities (CRA). Vertex. 2015;26:85-91.

24. Pacek LR, Mauro PM, Martins SS. Perceived risk of regular cannabis use in the United States from 2002 to 2012: differences by sex, age, and race/ ethnicity. Drug Alcohol Depend. 2015;149:232-244.
25. Ehlers CL, Gizer IR, Vieten C, et al. Cannabis dependence in the San Francisco Family Study: age of onset of use DSM-IV symptoms, withdrawal, and heritability. Addict Behav. 2010;35:102-110.

26. Hernandez-Avila CA, Rounsaville BJ, Kranzler HR. Opioid-, cannabis- and alcohol-dependent women show more rapid progression to substance abuse treatment. Drug Alcohol Depend. 2004;74:265-272.

27. Khan SS, Secades-Villa R, Okuda M, et al. Gender differences in cannabis use disorders: results from the National Epidemiological Survey of Alcohol and Related Conditions. Drug Alcohol Depend. 2013;130:101-108.

28. Ridenour TA, Lanza ST, Donny EC, et al. Different lengths of times for progressions in adolescent substance involvement. Addict Behav. 2006;31:962-983.

29. Scheipis TS, Desai RA, Cavallo DA, et al. Gender differences in adolescent marijuana use an associated psychosocial characteristics. J Addict Med. 2011;5:65-73.

30. Westermeyer J, Boedicker AE. Course, severity, and treatment of substance abuse among women versus men. Am J Drug Alcohol Abuse. 2000;26:523-535

31. Substance Abuse and Mental Health Services Administration, Center for Behavioral Health Statistics and Quality. The TEDS Report: gender differences in primary substance of abuse across age groups. Rockville, MD. Available at www.samhsa.gov/data/sites/default/files/sr077-genderdifferences-2014.pdf (last accessed on April 3, 2014).

32. Herrmann ES, Weerts EM, Vandrey R. Sex differences in cannabis withdrawal symptoms among treatment-seeking cannabis users. Exp Clin Psychopharmacol. 2015;23: 415-421.

33. Levin $\mathrm{KH}$, Copersino ML, Heishman, SJ, et al. Cannabis withdrawal symptoms in non-treatment-seeking adult cannabis smokers. Drug Alcohol Depend. 2010;111:120-127.

34. Hasin DS, Keyes KM, Alderson D, et al. Cannabis withdrawal in the United States: a general population study. J Clin Psychiatry. 2008;69:1354-1363.

35. Agrawal A, Pergadia ML, Lynskey MT. Is there evidence for symptoms of cannabis withdrawal in the National Epidemiologic Survey of Alcohol and Related Conditions? Am J Addict. 2008;17:199-208.

36. Copersino M, Boyd SJ, Tashkin DP, et al. Sociodemographic characteristics of cannabis smokers and experience of cannabis withdrawal. Am J Drug Alcohol Abuse. 2010;36:311-319.

37. Mathew RJ, Wilson WH, Davis R. Postural syncope after marijuana: a transcranial Doppler study of hemodynamics. Pharmacol Biochem Behav. 2003;75:309-318

38. Cooper ZD, Haney M. Investigation of sex-dependent effects of cannabis in daily cannabis smokers. Drug Alcohol Depend. 2014;136:85-91.

39. Haney M. Opioid antagonism of cannabinoid effects: differences between marijuana smokers and nonmarijuanasmokers. Neuropsychopharmacology. 2007;3:1391-1403.

40. Fogel JS, Kelly TH. Sex differences in the subjective effects of oral $\Delta_{9}$-THC in cannabis users. Pharmacol Biochem Behav. 2016; DOI: 10.1016/ j.pbb.2016.01.007.

41. Penetar DM, Kouri EM, Gross MM, et al. Transdermal nicotine alters some of marihuana's effects in male and female volunteers. Drug Alcohol Depend. 2005;79:211-223.

42. Makela $\mathrm{P}$, Wakeley J, Gijsman $\mathrm{H}$, et al. Low doses of $\Delta-9$ Tetrahydrocannabinol (THC) have divergent effects on short-term spatial memory in young, healthy adults. Neuropsychopharmacology. 2006;31:462-470.

43. Pope HG, Jacobs A, Mialet JP, et al. Evidence for a sex-specific residual effect of cannabis on visuospatial memory. Psychother Psychosom. 1997; 66:179-184.

44. Pope HG, Yurgelun-Todd D. The residual cognitive effects of heavy marijuana use in college students. JAMA. 1996;275:521-527.

45. Crane NA, Schuster RM, Gonzalez R. Preliminary evidence for a sexspecific relationship between amount of cannabis use and neurocognitive performance in young adult cannabis users. J Int Neuropsychol Soc. 2013;19:1009-1015.

46. Crane NA, Schuster RM, Mermelstein RJ, et al. Neuropsychological sex differences associated with age of initiated use among young adult cannabis users. J Clin Exp Neuropsychol. 2015;37:389-401.

47. King GR, Ernst T, Deng W. Altered brain activations during visuomotor integration in chronic active cannabis users: relationship to cortisol levels. J Neurosci. 2011;31:17923-17931.

48. Lisdahl KM, Price JS. Increased marijuana use and gender predict poorer cognitive functioning in adolescents and emerging adults. J Int Neuropsychol Soc. 2012;18:678-688. 
49. Tabachnick BG, Fidell LS. Using multivariate statistics, 4th ed. Allyn and Bacon: Boston, MA, 2001.

50. Riba J, Valle M, Sampedro F, et al. Telling true from false: cannabis users show increased susceptibility to false memories. Mol Psychiatry. 2015;20: 772-777.

51. Sewell RA, Schnakenberg A, Elander J, et al. Acute effects of THC on time perception in frequent and infrequent cannabis users. Psychopharmacology. 2012;226:401-413.

52. Miller CC, Murray TF, Freeman KG, et al. Cannabinoid agonist, CP 55,940, facilitates intake of palatable foods when injected into the hindbrain. Physiol Behav. 2004;80:611-616.

53. Diaz S, Farhang B, Hoien J, et al. Sex differences in the cannabinoid modulation of appetite, body temperature and neurotransmission at POMC synapses. Neuroendocrinology. 2009;89:424-440.

54. Esfandyari T, Camilleri M, Ferber I, et al. Effect of a cannabinoid agonist on gastrointestinal transit and postprandial satiation in healthy human subjects: a randomized, placebo-controlled study. Neurogastroenterol Motil. 2006;18:831-838.

55. Bolla KI, Lesage SR, Gamaldo CE, et al. Polysomnogram changes in marijuana users reporting sleep disturbances during prior abstinence. Sleep Med. 2010;11:882-889.

56. Nielsen $T$, Stenstrom $P$, Takeuchi $T$, et al. Partial REM-sleep deprivation increases the dream-like quality of mentation from REM sleep and sleep onset. Sleep. 2005;28:1083-1090.

57. Klosterhalfen S, Kellermann S, Pan F, et al. Effects of ethnicity and gender on motion sickness susceptibility. Aviat Space Environ Med. 2005;76:1051-1057.

58. Lawther A, Griffin MJ. A survey of the occurrence of motion sickness amongst passengers at sea. Aviat Space Environ Med. 1988;59:399-406.

59. Turner M, Griffin MJ, Holland I. Airsickness and aircraft motion during short-haul flights. Aviat Space Environ Med. 2000;71:1181-1189.

60. American Psychiatric Association. Diagnostic and statistical manual of mental disorders, 5th ed. American Psychiatric Association: Washington, DC, 2013.
61. Chang L, Heitkemper MM. Gender differences in irritable bowel syndrome. Gastroenterology. 2002;123:1686-1701.

62. American Psychological Association. All pain is not the same: psychologist discusses gender differences in chronic pain. Available at www.apa.org/news/press/releases/2010/08/gender-pain-differences aspx (last accessed August 12, 2010)

63. Case A, Paxson C. Sex differences in morbidity and mortality. Demography. 2005;42:189-214.

64. Finocchi C, Strada L. Sex-related differences in migraine. Neurol Sci. 2014;35 Suppl 1:207-213.

65. Golub A, Johnson BD, Dunlap E. The race/ethnicity disparity in misdemeanor marijuana arrests in New York City. Criminol Public Policy. 2007:6:131-164.

66. Ramchand R, Pacula RL, Iguchi MY. Racial differences in marijuanausers apos; risk of arrest in the United States. Drug Alcohol Depend. 2006;84:264-272.

Cite this article as: Cuttler C, Mischley LK, Sexton M (2016) Sex differences in cannabis use and effects: a cross-sectional survey of cannabis users, Cannabis and Cannabinoid Research 1:1, 166-175, DOI: 10.1089/can.2016.0010.

\section{Abbreviations Used}

IBS = irritable bowel syndrome

$\mathrm{n} / \mathrm{a}=$ not applicable

$\mathrm{REM}=$ rapid eye movement

$\mathrm{THC}=$ tetrahydrocannabinol

\section{Publish in Cannabis and Cannabinoid Research}

Cannabis and

Cannabinoid

Research
- Immediate, unrestricted online access

- Rigorous peer review

- Compliance with open access mandates

- Authors retain copyright

- Highly indexed

- Targeted email marketing

liebertpub.com/can 